\title{
A Critical Appraisal of Multicultural Awareness in Higher Education Institutions in the Philippines: Towards a Framework for Equity Pedagogy
}

\author{
Von L. Sarino \\ Olivarez College, Philippines
}

\begin{abstract}
The influx of foreign students in Higher Education Institutions (HEIs) in the Philippines requires administrators, teachers, staff, and students to be cognizant of the multicultural health of their campuses. On this ground, the paper presents results of the Sense of Awareness on Multicultural Education Inventory and the implications of the findings towards institutional transformation. The mixed-method study involved 453 respondents from five HEIs with the most number of foreign students. The research undertaking was anchored on the Foundational Elements of Multicultural Education as proposed by James Banks (2008) vis-à-vis the Multicultural Thinking Skills Continuum as conceived by the author. Moreover, the study puts forward a framework for equity pedagogy which includes strategies to develop Higher Order Multicultural Thinking Skills as well as institutional guidelines aimed at fostering a healthy multicultural environment in HEIs in the Philippines and beyond.
\end{abstract}

\section{Introduction}

The upsurge in student mobility has caused a dramatic change in the Philippine educational demographic landscape. The past two decades witnessed more international students enrolling in in the University of the Philippines, De La Salle University, Ateneo de Manila University, and St. Louis University, among others (Commission on Higher Education, 2009). Inevitably, one significant consequence of this global phenomenon is multiculturalism, whereby students of varied nationalities, cultures, religions, and belief systems share the same classrooms, laboratories, and other school facilities while overcoming language barriers, social stereotypes, and not to mention, while concurrently going through the emotional, psychosexual, and physiological transition from adolescence to adulthood. Accordingly, the question of readiness is brought to the fore to critically appraise whether or not Philippine HEIs have put forward policies, programs, and effective monitoring schemes aimed at promoting and ensuring the most conducive multicultural learning environment for both foreign and local students.

In 2009, there were 2.5 million students studying outside their own country and will rise approximately to 7 million by year 2020 (www.unesco.org). In the Philippines, as of August, 2011, out of more than 26,000 foreign students, there are more than 17,000 enrolled in various HEI's wherein South Koreans topped the list, numbering 11,612, followed by 3,961 Chinese and 3,225 Iranians (http://immigration.gov.ph/). According to the Commission on Higher Education, there are fifty (50) private HEIs granted autonomous and deregulated status who accept foreign students. Foreign students are also accommodated by 229 private HEIs that offer a total of 1,207 accredited programs and courses. Furthermore, according to Angeles [2], foreign students in the Philippines usually enroll in the following top 10 higher education programs: business administration, dental medicine, nursing, hotel and restaurant management, medicine, and others.

This paradigm shift in the educational system of different countries brought about by globalization requires a new wave of school leadership. Accordingly, the 'one size fits all' leadership style of the past may no longer be relevant in the global academic village - an academic community of varied cultures whose students recognize that "they will live and work in a world-wide context, and thus seek to master the knowledge and competencies to equip themselves to succeed in this transnational setting" [7], of which in this study pertains to multiculturalism.

Given the existing scenario, questions may arise on how school leaders of higher education create a nurturing environment for local and foreign students: Are they [local and foreign students] on equal footing and aligned to the thrust of producing equally promising individuals who can compete globally? How do their institutions respond to the needs of students, faculty and the diverse communities in such a way that each entity has the ability to prosper in the interconnected milieu? These are queries that educators in all school set-ups must seriously consider.

In the local scene, the Office of the International Student Program, an adjunct office of the Vice Chancellor for Student Affairs of the University of the Philippines-Diliman, provides its own International Students Program Handbook. The contents of the handbook include not only immigration requirements but also "Rules and Regulations on Conduct and Discipline” (pp. 20-21). These rules and regulations are similar in every way to those provided for local students. 
The exodus of foreign students to the Philippines poses a great challenge to school leaders as globalized-multicultural education inevitably necessitates a revisit of curriculum content, pedagogical modalities, and administrative styles and to identify warranted adjustments thereof to suit the needs of the multicultural academic community.

Multiculturalism in schools, which has become the consequence of the change in the Philippine educational demographic landscape, greatly affects the teaching and learning environment. This poses the same challenge to the teachers, the Filipino or local students, the foreign students and the school administrators, collectively. The readiness of each sector of the academe as regards the presence of foreign students and the policies and guidelines they have to submit themselves to must be logically and objectively addressed by host schools. Furthermore, change in the teaching and learning environment whereby foreign students occupy the same classrooms with Filipino students create multiplicity of characters and personalities in the place.

All these point to the fact that there must be clear - cut policies to help build a school-friendly environment supportive of students' rights and respectful of students' culture. In the same vein, understanding the diverse cultural, linguistic, and educational needs of students is essential to creating genuinely inclusive and effective HEI's where all students can thrive. This includes embracing individuality in diverse learners and their families, as well as understanding the cultural foundations of learning and behavior. Are we providing the foreign students the real comfort zone for learning and the justification of why they deserve to be in the Philippines?

With this contention in mind, this researcher conducted a study to determine the sense of awareness on multicultural education in HEI's and its implications to institutional transformation. Moreover, the researcher had the humble intention of forwarding suggestions and recommendations towards the development of Higher-Order Multicultural Thinking Skills [16] with the intent of sublimating and cultivating metacognitive strategies to level up the playing field in a multicultural teaching-learning environment.

\section{Method}

In this mixed method study, the researcher simultaneously gathered both quantitative and qualitative data, merged them using both quantitative and qualitative analysis method, and then interpreted the results together to provide a better understanding of the phenomena. Therefore, direct and indirect interviews were conducted by the researcher. In addition, Focus Group Discussions were conducted with concerned participants alongside naturalistic observation.

\section{Participants}

The total population or universe of the study came from the school leaders, faculty members, foreign and local students, and academic support staff of five (5) HEI's in the Luzon, Philippines. Selected HEIs refer to five (5) of the top 15 tertiary level schools in the Luzon, Philippines with the most number of foreign students (CHED 2004). These HEIs were St. Louis University in Baguio City (SLU), with 203 foreign students; University of Baguio (UB), with 195 foreign students; University of Perpetual Help system DALTA in Las Piñas City (UPHSD), with 186 foreign students; Adamson University (AU) in Manila with 119 foreign students; and Adventist University of the Philippines in Silang, Cavite (AUP), with 180 foreign students. The choice of the aforesaid HEIs were based on HEIs willingness to participate in the study while taking into account their standing in the CHED database on foreign student population in HEIs located in Luzon (CHED 2004). All respondents from the aforementioned HEIs were chosen using the convenience sampling technique.

\subsection{Materials and Procedure}

This study made use of two sets of questionnaires: one elicited vital demographic information about the respondents, and the other, a research-designed instrument meant to appraise the sense of awareness on multicultural education of the respondents.

\subsubsection{Section A. HEI Stakeholders' Profile}

This part explored the personal data of the five (5) groups of respondents. Characteristics of each category of respondents were asked, such as, age; gender; nationality, academic qualifications; designation; and number of years of school work experience.

\subsubsection{Section B. Sense of Awareness on Multicultural Education Inventory (S. A. M. E.)} SAME or Sense of Awareness on Multicultural Education is a concept that the researcher purported to determine whether an individual's depth of consciousness on the nature and tenets of multicultural education falls under cursory, augmented, advocating, active, or metacognitive continua. Specifically, in this study, the researcher intended to appraise, through the analysis of the results of the SAME Inventory, the HEIs and their stakeholders' readiness to participate in a diverse academic community, taking into account the influx of foreign students in the participating institutions. 
In conceiving the SAME, the researcher logically assumed that determining the "sense of awareness" went deeper and beyond "level" since in this study, "sense” suggested consciousness, cognizance, perception, metacognitive strategies, and philosophies that an individual possesses or assumes which serve as determinants of a person's or an HEI's preparedness to deal with adjustments that might be warranted to ensure equity for foreign and local students.

The Sense of Awareness on Multicultural Education Inventory or SAME is a 40-item instrument designed by the researcher and uses a 5point Likert Scale to ascertain the sense of awareness on the nature and tenets of multicultural education of stakeholders of HEIs. The items that appear in the SAME are 40 statements of beliefs, assumptions, actions, and contemplations regarding multicultural education in HEIs, specifically taking into account the influx of foreign students in the participating campuses. Each of the eight foundational elements is provided with five statements--each corresponding to the depths of the respondent's SAME. Five versions of the instrument were designed to report the sense of awareness on multicultural education of HEI stakeholders, namely, school leaders, faculty members, academic support staff, local students, and foreign students.

Figure 1 below illustrates the continuum within which the 8 Foundational Elements of Multicultural Education operates vis-à-vis the echelon of multicultural thinking skills.

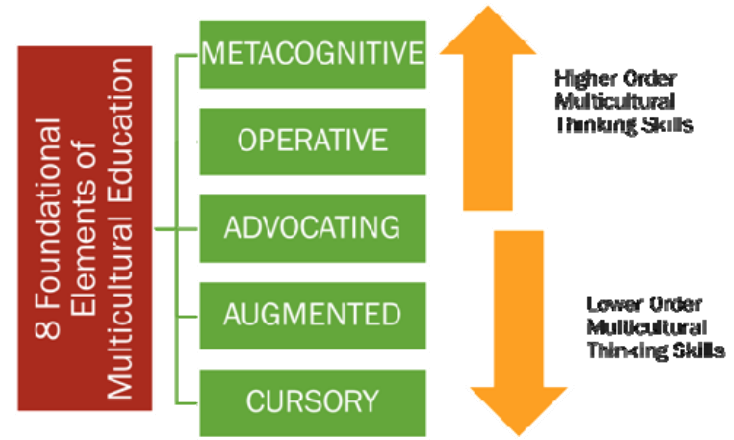

Figure 1. S.A.M.E Continuum (Sarino, 2011)

\section{Sense of Awareness on Multicultural Education Continuum}

In an attempt to classify the sense of awareness on multicultural education of HEI stakeholders, the researcher put in place the Sense of Awareness on Multicultural Education Continuum [16] which ranged from cursory, augmented, advocating, active, or metacognitive awareness. These gradients are detailed below:

\section{Cursory Awareness}

In this continuum, the HEI stakeholder possesses notions and concepts about multicultural education that do not necessarily correspond with the ideals of multiculturalism. These potentially erroneous notions, which may have been brought about by lack of adequate information and exposure to various cultures, may therefore be typified as naïve, superficial, or cursory awareness.

\section{Augmented Awareness}

Through exposure to the essentials of multiculturalism and multicultural education, whether through media, books, oversea travel, and contact with other cultures, the HEI stakeholder, in this continuum, has developed an augmented awareness of multicultural education. Thus, the HEI stakeholder with an augmented awareness values diversity, synergism, pluralism, and tolerance.

\section{Advocating Awareness}

Advocacy is a process that takes one's awareness, beliefs, knowledge, and acknowledgment and transforms them into a plan for effecting change. In a multicultural context, it becomes a set of systemic interventions that promote transformational change toward multiculturalism. The HEI stakeholder who possesses advocacy show a commitment to improving the lives of students by supporting positions and policies that promote the best interests of foreign and local students today, tomorrow, and into the future.

\section{Operative Awareness}

Operative awareness is advocacy in action. This is the sense of awareness where the advocacy takes form and is realized in practice. Action is the act and art of doing something in a proactive way to promote multiculturalism. It can be a seen as a willingness to speak out on behalf of a cohort of voiceless students, foreign and local alike. Action involves a conscious, intentional, and deliberate act or activity whose outcome benefit both foreign and local students.

\section{Metacognitive Awareness}

Metacognitive awareness is the highest sense of awareness. It involves self-monitoring, selfrepresentation, and self-regulation processes that an individual uses in ensuring that he/she lives the ideals of multicultural education and affects or influences other people in the process. In practice these capacities are used to regulate one's own cognition, to maximize one's potential to think, learn and to the evaluation of proper ethical/moral rules that govern multicultural education.

\section{Results}

\subsection{On the demographic characteristics of the five groups of respondents:}

\subsubsection{School Leaders}

Majority of the school leader-respondents belonged to age ranges $29-39$ and $40-50$ years old. In terms of gender, school leaders who participated in 
the study were almost split in half. Thirty-nine school leaders in this study were Master's degree holders who. Twenty-four school leaders were Doctorate degree holders. More than $50 \%$ of the participating school leaders had 1-5 years of administrative experience. Almost all school leaders who participated in this study were full time employees of their respective HEIs.

\subsubsection{Faculty}

Most faculty respondents fell under age ranges 18-28 and 29-39. Almost half and half of the faculty respondents were males and females. A large chunk of the faculty respondents were Master's Degree holders numbering to 81 out of 101. 48 faculty respondents had 6 to 10 years of teaching experience while 31 had 1 to 5 years of teaching experience. Majority of the faculty respondents were full time employees of their respective HEIs numbering to 74 . 38 faculty respondents taught English as a general education subject while 11 taught Math; 16 taught Humanities; 12 taught Science; while the remaining 24 taught other general education subjects.

\section{Academic Support Staff}

Majority of the non-teaching staff respondents belonged to age range 18 to 28 . Male and female non-teaching staff respondents were almost split in half. All non-teaching staff respondents were baccalaureate degree holders. 39 non-teaching staff respondents had 1 to 5 years of academic support experience while 17 had 6 to 10 years of academic support experience. All non-teaching staff respondents were full time employees of their respective HEIs.

\section{Local Students}

101 local students fell under age range 15 to 18 while 40 fall under age range 19-23. The current study surveyed 83 female local student respondents and 68 male local student respondents.

\section{Foreign Students}

A large chunk of foreign student respondents in this study were South Koreans comprising 40 individuals. 5 were Chinese; 2 were Iranians; 9 were Indians; while 24 individuals belong to other nationalities. There were more male foreign student respondents than female foreign student respondents. 37 foreign student respondents have been staying in the Philippines for less than a year while 31 foreign student respondents have been staying for 1 to 2 years and 11 foreign student respondents have been staying for the past 3 to 4 years.
4.2 On the sense of awareness on multicultural education of the five groups of respondents in response to the S.A.M.E Inventory:

\subsubsection{As per Sense of Awareness on Multicultural Education Continuum}

Generally, the respondents agreed with the cursory sense statements. Moreover, it is observable that all stakeholders have almost similar degrees of agreement with the statements under cursory sense of awareness. This agreement presupposes that the respondents have gone beyond cursory awareness.

\section{Augmented Sense of Awareness}

Largely, the respondents have achieved an augmented sense of awareness. Comparable with the responses under cursory sense of awareness, it is observable that all stakeholders have almost similar degrees of agreement with the statements under augmented sense of awareness. These results suggest that the respondents have overcome cursory sense of awareness and have developed a better grasp of multicultural education.

\section{Advocating Sense of Awareness}

By and large, the respondents do advocate multicultural education. This suggests that indeed, the five groups of respondents do not only possess an augmented sense of awareness, but also advocates the idea of multicultural education. Furthermore, the respondents, as evidenced by the analogous means of each group, may have committed themselves to supporting positions that uphold multiculturalism in schools.

\section{Operative Sense of Awareness}

Most respondents except teachers were uncertain with their responses to statements under operative sense of awareness. This may mean that most respondents may have remained advocates of the cause and may have limited actual involvement in promoting the tenets of multicultural education. On the other hand, it is refreshing to note that the faculty-respondents, in comparison with the other groups of respondents, have had active involvement in matters concerning multicultural education.

\section{Metacognitive Sense of Awareness}

All groups of respondents are uncertain or unaware as to whether they have achieved a level of awareness on multicultural education that pushes them to regulate their own thinking and actions that 
ensure equity and fairness with regards to dealing with foreign and local students in the academic community. Likewise, the results suggest that the respondents have yet to develop what the researcher calls "higher order multicultural thinking skills."

\subsubsection{As per Foundational Elements of Multicultural Education}

\section{Foundational Element A}

Respondents by and large agree that stakeholders of HEIs must have high expectations for and positive attitudes toward local and foreign students. Specifically, Local students and foreign students strongly agree that student performance is not always determined by specific environmental exposure and racial characteristics, thus, expectations towards spirit potential must not be based on country of origin and race. Moreover, almost all respondents appear to have been actively involved in organizing and participating in activities that promote equal and positive treatment of foreign and local students like meetings, forums, symposia, and seminars with multicultural themes. Conversely, non-teaching staff respondents seem to have had limited exposure to the aforesaid activities.

\section{Foundational Element B}

The five groups of the respondents agree with the statements that concur with the idea that formulized curriculum should reflect the experiences, cultures, and perspectives of both foreign and local students. School leaders strongly agree that there is a need to constantly adjust the existing curriculum to suit foreign and local students. Alternatively, as to whether the respondents actively organize or participate in efforts to revisit and enhance the existing curriculum to ensure that specific needs of local and foreign students are met, four out of the five groups of respondents responded neither agree nor disagree. It seemed that only the faculty members have actively organized and participated in the aforesaid efforts. Finally, all respondents were uncertain whether they constantly reflect on whether or not the curriculum considers perspectives of both foreign and local students and that the curriculum respects differences in beliefs, religions, and traditions.

\section{Foundational Element C}

Faculty, Non-Teaching Staff, Local Students and Foreign student respondents alike Strongly Agree that teachers must look into the cultural differences between local and foreign students when adopting teaching styles. School leaders on the other hand Agree with the same statement.
Advocating the idea that the choice of teaching styles must also be based on the variety of the cultures present in the classroom is clearly indicated by the strong agreement of non-teaching staff and foreign student respondents. As to whether the respondents, before employing teaching styles for a class of foreign and local students teachers must research on students cultural and religious backgrounds on the belief that learning styles and motivation are affected by such backgrounds, School leaders, Faculty Members, and Non-Teaching Staff respondents remain uncertain.

\section{Foundational Element D}

School Leaders and Faculty and foreign student respondents Agree that foreign students must not be required to learn to communicate in Filipino and should be allowed to use their first language during conversations. Conversely, Non-Teaching Staff and Local Students Neither Agree nor Disagree with the said idea.

Advocating respect to both foreign and local students by allowing the use of first languages and dialects is agreed upon by non-teaching and foreign students. However, School Leaders and Local Students Neither Agreed nor Disagreed while Faculty respondents disagreed with the statement.

With regards to whether the respondents let local and foreign students use first languages and dialects, Faculty, Non-Teaching, Local students, Foreign Students Neither Agreed nor Disagreed. School leaders at the other end of the pole Disagreed with the statement. In effect, the school leader respondents do not allow the use of first languages and dialects.

\section{Foundational Element E}

School Leaders, Faculty, Non-Teaching Staff, and Local Students Strongly Agreed that instructional materials should showcase our cultures present in the classroom. Meanwhile, as to whether the respondents actually use books, films, news clippings, and reference materials that show events, situations, and concepts from the perspectives of both foreign and local students, school leaders, non-teaching staff, and local teacher respondents Neither Agreed nor Disagreed.

\section{Foundational Element F}

Unanimously, the respondents strongly agreed that foreign students like local students should be entitled to be included in the dean's list and other academic privileges. With regards to advocating the aforesaid idea, all five groups Agreed. Similarly, with regards to the idea that results of student evaluation must remain fair for both foreign and 
local students, the respondents agreed. It is however confusing to know that some respondents may find it a challenge evaluating the performance of both foreign and local students as indicated by the Neither Agree nor Disagree mean scores garnered by School leaders, Local Students, Foreign Students.

\section{Foundational Element G}

All respondents strongly agree that academic institutions must make certain that religious traditions represented in the school are respected. This also holds through with the assumption that academic institution is a rich tapestry of culture woven of all the different cultural and ethnic heritages represented in the school as indicated by the strong agreement of all five groups.

As to the belief that the respondents must help promote cultural diversity in the academic institution and must combat ethnocentrism and other forms of racism and discrimination, the respondents either strongly agreed or agreed. Meanwhile, some respondents organize or participate in activities that celebrate cultural and religious diversity whenever possible to become familiar with for example, India’s Diwali Festivals, Islam’s Ramada, Christians' Christmas, Korea's Harvestmoon festival, etc. However, it is also evident that non-teaching staff and local students are uncertain whether they have participated on the aforesaid activities.

\section{Foundational Element $\mathbf{H}$}

It was highly observable that all five groups of respondents unanimously and strongly agreed that academic institutions should concern themselves with the career goals of both foreign and local students and that school leaders must know the individual potential of students and help them actualize that potential.

As to advocating the belief that one must promote high expectations for students both local and foreign to help students set and realize positive career goals, the respondents either strongly agreed or agreed.

With regards to whether the respondents actually offer and provide career advises for both foreign and local students, it is observable that only school leaders and faculty members agree while nonteaching staff, local students, and foreign students neither agreed nor disagreed.

Finally, as to whether the respondents contemplate on students' future after college and envision both foreign and local students working side by side in their own fields of expertise and decide on ways to help students reach their goals, school leaders and faculty members Agreed. Meanwhile, non-teaching staff, local students, and foreign students neither agreed nor disagreed on the said assumption.
4.3 Significant differences on the sense of awareness on multicultural education of the five groups of respondents:

As per Sense of Awareness on Multicultural Education Continuum

With regards to Cursory Sense of Awareness, since the significance is .043 or below .05, the hypothesis is rejected. Thus, there exist significant differences appertaining to responses under Cursory Sense items.

On the other hand, the null hypothesis is accepted in the case of the responses under augmented sense of awareness as indicated by the significance value that is 0.972 or higher than .05. Likewise, responses under advocating sense of awareness possess no significant differences as indicated by the value 0.716 or above .05 suggesting acceptance of the null hypothesis.

Responses to items under operative sense of awareness possess significant differences as indicated by the value .003 or less than .05 which suggests rejection of the null hypothesis.

Finally, responses to items under Metacognitive Sense of Awareness possess no significant differences as indicated by the value 0.988 or above 0.05 thus accepting the null hypothesis.

\subsubsection{As per Foundational Elements of Multicultural Education}

Responses of the five groups of respondents under Foundational Element A possess no significant differences as indicated by the value 0.130 thus accepting the null hypothesis.

Likewise, in the case of the responses under Foundational Element $\mathrm{B}$, the null hypothesis is accepted as indicated by the value of significance that is 0.808 or no significant differences. Similarly, there are no significant differences as to the responses of the five groups of respondents to statements under Foundational Element $\mathrm{C}$ as indicated by the value of significance that is 0.956 or no significant differences.

However, in the case of the responses of the five groups of respondents under Foundational Element $\mathrm{D}$, the null hypothesis is rejected as indicated by the value of significance that is 0.018 or less than 0.05 . Thus there exist significant differences. In the case of Foundational Element E, the null hypothesis is accepted. Meaning there are no significant differences as to the responses of the five groups of respondents as indicated by the value of significance that is 0.850. Similarly, the null hypothesis is accepted in the case of the responses for Foundational Element $\mathrm{F}$ as the value of significance is 0.725 .

In the same manner, responses of the five groups of the respondents under the Foundational Element $G$ 
possess no significant differences as indicated by the value of the significance that is 0.661. Finally, Foundational Element $\mathrm{H}$ and the responses of the five groups of respondents thereof accept the null hypothesis. Accordingly, there are no significant differences as indicated by the value of significance that is 0.872 .

\subsection{On the implications to institutional transformation of the sense of awareness on multicultural education of the five groups of respondents:}

The results of the study vividly provide a scenario where stakeholders of HEIs, school leaders, faculty members, academic support staff, local students, and foreign students advocate multicultural education. Similarly though, the same stakeholders, admittedly, have limited opportunities to realize and actuate the said advocacy. This typifies a multicultural academic community that is in need of opportunities where multicultural education is further explored, such as through seminars, symposia, and other pertinent activities.

Although several participating HEIs claimed to have opened offices specifically designed to address the needs of foreign students, it was likewise observable, as a result of unstructured interviews, that these offices rendered services limited to technical issues concerning foreign students, such as visa extension, enrolment, language assistance, and the like. However, in matters concerning personal and social adjustments to the new and foreign learning environment and the multicultural challenges that these foreign students have to face, the aforesaid offices seem to fall short.

Furthermore, considering that adjustments regarding the presence of foreign students in the campuses involve local students and other front liners in the academic community as well, it is warranted that multicultural education also is at the forefront of HEIs' concern.

In the same vein, equity pedagogy seemed to be an uncharted territory for some faculty-respondents. Although quantitative data analysis showed that some teachers have surpassed advocating sense of awareness and have actually immersed themselves in activities tackling multicultural education, unstructured interviews still project that some teachers may not be aware that some pedagogical modalities that they employ may directly or indirectly promote racism and other forms of discrimination.

All these and more denote that HEIs necessitate first, a revisit of the existing curriculum, in order to make necessary adjustments aimed at fostering multicultural education and integrating the same in the design of the curriculum. Secondly, it would be essential to develop strategies to develop Higher
Order Multicultural Thinking Skills among HEI stakeholders, with the end-in-view that starting the change from within, or from the grass roots level, a nurturing and caring environment for diverse groups in the academic community and beyond may be cultivated. Thus, the necessary recommendations are put forward in the succeeding parts of this document.

\section{Discussion}

In order to address the issue concerning the lack of multicultural metacognitive skills in HEI's as indicated in the abovementioned results of the S.A.M.E. Inventory, it would be beneficial to develop a framework for Equity Pedagogy by first, (1) putting forward strategies to develop higherorder multicultural thinking skills (HOMTS) that would be applicable and beneficial to all five groups of respondents and (2) considering the inclusion of multicultural education in HEI policies. To wit:

\subsection{Developing Higher Order Multicultural Thinking Skills (HOMTS)}

Higher-order multicultural thinking skills include critical, logical, reflective, metacognitive, and creative thinking and promote an environment of respect and equity between and among diverse communities within an academic organization. These skills are activated when stakeholders in the academic community encounter unfamiliar problems, uncertainties, questions, or dilemmas in the multicultural environment. Successful applications of the skills result in explanations, decisions, performances, and products that are valid within the context of available knowledge and experience and that promote continued growth in multicultural skills. Higher- order multicultural thinking skills are grounded in lower order skills such as discriminations, simple application and analysis, and cognitive strategies and are linked to prior knowledge of diverse communities within and outside the academe. Appropriate teaching strategies and learning environments facilitate their growth as do student persistence, self-monitoring, and openminded, flexible attitudes. In the case of HOMTS, every stakeholder in the academic community is considered a student of multicultural education.

\section{Informed Cross-Cultural Interaction}

Developing Higher- Order Multicultural Thinking is the process in which a person develops competencies in multiple ways of perceiving, evaluating, believing, and solving problems related to diversity within and outside the multicultural academic community. The purpose is to focus on understanding and learning to negotiate cultural diversity among stakeholders in HEIs by becoming aware of one's own perspectives as well as becoming 
conscious of other cultural perspectives as a foundation of informed cross-cultural interaction.

\section{Curriculum Reform}

Secondly, the curriculum needs to be reformed with inclusion of curriculum theory and historical inquiry so that bias in textbooks, media, and other educational materials can be detected easily by educators, students, and other stakeholders. Curriculum reform strives to expand the traditional course contents that are primarily monoethnic and Anglo-European through inclusion of multiethnic and global perspectives. For most educators, this reform requires active inquiry and development of new knowledge and understanding of the historical contributions of contemporary and past ethnic groups to the current body of knowledge in the content areas and academic disciplines.

\section{Equity Pedagogy}

Equity pedagogy becomes an important component of multicultural reform. Equity pedagogy aims at achieving fair and equal educational opportunities for all of the nation's children, including socio-economically disadvantaged and ethnic minorities in the microcultures. It attempts to transform the total school environment, especially the hidden curriculum that is expressed in teacher expectations for student learning and the differential disciplinary policies and practices and related community relations by reversing these trends and by addressing the problems that these underrepresented students face.

Equity pedagogy also requires that educators develop an understanding of the different learning styles students develop from their own cultural upbringing so that educators can employ alternative instructional strategies to help all students learn the key concepts, principles, facts, and generalizations in the various content areas and academic disciplines. To be able to do this, educators will need to develop pedagogical knowledge, skills, and dispositions that allow them to adapt alternative teaching methods or modify instructional strategies in culturally diverse classrooms. Equity pedagogy is to ensure the attainment of the highest standards in academic excellence among all students. School and classroom climates must also be changed so that academic success is achievable by students from all cultural groups.

\section{Teaching toward Social Justice}

Lastly, but not least, teaching toward social justice requires adequate understanding of the demographics of the students, culture, and race in popular culture, and development of social action skills. It also emphasizes the clearing up of myths and stereotypes associated with gender, age, and the various races and ethnic groups by stressing basic human similarities (Nieto, 1996). In addition, teaching toward social justice promotes developing an awareness of the historical roots and an understanding of the evidence of individual and institutional prejudice and discriminations such as cultural racism, sexism, classism, and other forms of prejudice and discrimination.

\subsection{Inclusion of Multicultural Education Policies}

The presence of young people from such a wealth of backgrounds and experience in the Philippine HEIs presents particular challenges - challenges that are yet to be met by our HEIs.

Valuing and building on cultural and linguistic diversity, and further developing the language skills of foreign and local students, assist in empowering young people to develop as confident citizens of the world.

Racial intolerance and discrimination are counterproductive for both practical and ethical reasons. Understanding cultural sensitivities is critical to success in education, business and civic life. Cultural and linguistic diversity is to be recognized, accepted and celebrated. It is to be used as an asset to enable students and staff to develop relationships based on respect and appreciation of the importance of differences in meeting the global challenges of the 21st Century.

Equipping HEI stakeholders to build effective relationships with one another, each coming from different cultural, linguistic and religious backgrounds is a key for improving student learning and the success of schools in a diverse community.

Accordingly, HEIs must be committed to:

1. assisting all students and staff to become informed, productive, adaptable, motivated and creative citizens, who take full advantage of their economic, social and individual opportunities;

2. building an accepting environment where all staff and students are treated with dignity and respect and where diversity is valued;

3. facilitating intercultural contact through broadening knowledge of the world and promoting the skills needed for cross-cultural cooperation and understanding; and

4. creating a learning environment where stereotypes are questioned and bias, bigotry, ethnocentrism, prejudice or racism are wholeheartedly rejected.

In meeting these commitments, HEIs must recognize the significance of cultural, linguistic and racial differences amongst all stakeholders.

Diversity brings significant educational benefits to all stakeholders and the wider community. It enables the creation of learning environments enriched by different life experiences, varied perspectives, dynamic interchange, flexibility and creativity. The skills and attitudes acquired by 
students in this environment are the same as those needed for the new worlds of work and community life. Schools can be, and generally are, model communities of mutual respect, harmony and tolerance.

\section{Conclusion}

The unanimity of the respondents as to their lack of metacognitive sense of awareness on multicultural education suggests a need to develop in them higherorder multicultural thinking skills (HOMTS). It is through the development of HOMTS that stakeholder of HEIs and the HEI as a whole may achieve a competitive advantage against other HEIs accepting foreign students.

In the light of the existing scenario of HEIs, having limited vision on multicultural education as should be reflected in the curriculum, a constant revisit and adjustment of the existing curriculum is warranted to ensure equity in pedagogy. Furthermore, results suggest a need for the inclusion of institutional policies appertaining to multicultural education.

For the few stakeholders who may have expressed their cursory or superficial awareness to multicultural education, it will be essential for them to be exposed, through the initiative and efforts of all stakeholders, to multiculturalism, to information regarding other races, nationalities, religions, and their similarities and differences. It must also be made clear to stakeholders the policies and guidelines governing the presence of foreign students in their campuses.

Stakeholders with Augmented Sense of Awareness should exert efforts to sublimate their level and realize that knowledge of multicultural education is not enough. Thus, constant exposure to multicultural situations is deemed essential if stakeholders are to consider deepening their sense of awareness to multicultural education.

Advocating a philosophy is analogous to planting a seed deep within one's thoughts. It should impact a person's decision-making regarding multicultural education. Thus, advocacy towards multicultural education serves as a starting point to promoting equity and unity in diversity. Accordingly, it will be beneficial to HEI stakeholders with Advocating Sense of Awareness to find ways to actualize and realize the ideals of multicultural education.

Considering that the HEI stakeholders stagnated in Advocating Sense of Awareness, it will be beneficial to find ways to expose themselves to activities that translates advocacy into action. These activities may be in the form of symposiums, fora, dialogues, and the like, aimed at promoting multicultural education and equity in the light of the relationships between and among foreign and local students.
In order to address the issue concerning the lack of actual exposure to multicultural curriculum as indicated in the abovementioned results of the S.A.M.E. Inventory, it would be beneficial to first, (1) consider the key characteristics of a multicultural curriculum, then, to (2) put forward strategies to develop higher- order multicultural thinking skills (HOMTS) that would be applicable and beneficial to all five groups of respondents and (3) to circumspect the inclusion of multicultural education in HEI policies.

\section{Recommendations}

The following recommendations were formulated grounded on the findings of the study and the conclusions drawn:

1. For the fair few stakeholders who may have expressed their cursory or superficial awareness to multicultural education, it will be essential to expose themselves, through the initiative and efforts of all stakeholders, to multiculturalism, to information regarding other races, nationalities, religions, and their similarities and differences. It must also be made clear to stakeholders the policies and guidelines governing the presence of foreign students in their campuses.

2. Stakeholders with augmented sense of awareness must exert efforts to sublimate their level and realize that knowledge of multicultural education is not enough. Thus, constant exposure to multicultural situations is deemed essential if stakeholders are to consider deepening their sense of awareness to multicultural education.

3. Advocating a philosophy is analogous to planting a seed deep within one's thoughts. It should impact a person's decision-making regarding multicultural education. Thus, advocacy towards multicultural education serves as a starting point to promoting equity and unity in diversity. Accordingly, it will be beneficial to HEI stakeholders with advocating sense of awareness to find ways to actualize and realize the ideals of multicultural education.

4. Considering that the HEI stakeholders stagnated in advocating sense of awareness, it will be beneficial to find ways to expose themselves to activities that puts advocacy into action. These activities may be in the form of symposiums, forums, dialogues, and the like all aimed at promoting multicultural education and equity in the light of the relationships between and among foreign and local students.

In order to address the issue concerning the lack of actual exposure to multicultural curriculum as indicated in the abovementioned results of the S.A.M.E. Inventory, it would be beneficial to first, (1) consider the key characteristics of a multicultural curriculum, then, to (2) put forward strategies to develop higher order multicultural thinking skills 
(HOMTS) that would be applicable and beneficial to all five groups of respondents and (3) to circumspect the inclusion of multicultural education in HEI policies.

Recommendations for Future Studies

1. Further study must be conducted to appraise the S.A.M.E of older faculty respondents. Moreover, it is deemed that information elicited from older (and presumably seasoned and expert) faculty members may contribute to understanding the transitions/development of M.E. in the country and thus may dictate the succeeding steps that need to be taken to foster the progression of multiculturalism here and abroad.

2. Another study must be conducted probing the relationships between subjects taught and S.A.M.E of the teacher with the intent of eliciting information regarding which teacher may prove most influential towards championing M.E.

3. S.A.M.E studies must be made with the inclusion of faculty members teaching major and professional subjects as they, too, may serve as effective tools in the advancement of M.E.

4. As front liners in HEIs, salient insights may be gained from older, more experienced academic support staff. Although results of their SAME are not deduced to be high, still, their stories on-the-job are deemed to provide significant inputs for the younger staff to learn from.

\section{Acknowledgements}

The researcher expresses his sincerest gratitude to Dr. Eric L. Olivarez, Vice President for Academics and Services and Mrs. Evangeline Olivarez-Ilas, Vice President for Finance and Administration of Olivarez College for the boundless support they have provided; to Dr. Elmer B. de Leon and Dr. Nieves M. Medina for their guidance in the conduct of this study; to the researcher's parents, Fernando and Elizabeth Sarino for the inspiration and moral support; to Prof. Charles Shoniregun of the Infonomics Society, for his trust and confidence, and finally and most importantly, to Jesus, the Divine Master, The Way, The Truth, and The Life...

\section{References}

[1] American Psychological Association (2002). Guidelines on multicultural education, training, research, practice, and organizational change for psychologists.

http://www.apa.org/pi/multiculturalguidelines.pdf

[2] Angeles, E. (2009). Student Mobility in Southeast Asia: the Philippine Experience. http://www.rihed.seameo.org/mbseminar/pre_philipp ine.pdf
[3] Banks, J. (2006). Cultural diversity and citizenship education: Foundations, curriculum, and teaching (5th ed.). Boston: Allyn \& Bacon.

[4] Banks, J. (2008). An introduction to multicultural education (4th ed.). Boston: Pearson Education.

[5] Banks, J. A., and Banks, C.A.M. (Eds.). (2001). Handbook of research on multicultural education (2nd ed.). San Francisco: Jossey-Bass.

[6] Bloom, B. S. (Ed). (1956). Taxonomy of educational objectives. New York: McKay.

[7] Collins, P. (1990). Black Feminist Thought:

Knowledge, Consciousness, and the Politics of Empowerment. New York: Routledge.

[8] Francisco, C. (2009). Educative Needs of Foreign Students in Higher Education Instituions: Basis for Multicultural Education. Olivarez College. Parañaque City.

[9] http://immigration.gov.ph

[10] http://www.unesco.org

[11] International Students Program Handbook (2002-2003). University of the Philippines-Diliman.

[12] Miksch, K. L., Higbee, J. L., Jehangir, R. R., Lundell, D. B., Bruch, P. L., \& Barajas, H. L. (2003). Multicultural Awareness Project for Institutional Transformation (MAP IT). Minneapolis, MN:

[13] Palispis, E. (2011). 21st Century Perspectives on Education. Trinity University of Asia. Quezon City.

[14] Santiago, A. (2005). Cross-Border Transactions in Higher Education: Philippine Competitiveness.

[15] Philippine Institute of Developmental Studies. NEDA, Makati City.

[16] Sarino, V. (2008). Epistemological Assumptions of Korean EFL Students: Their Effects on Language Learning Abilities and their Pedagogical Implications. UPHSD-GSE Journal. Las Piñas City. 